\title{
A Fast and Energy Efficient Synthesis of ZnO@RGO and its Application in Ni-Zn Secondary Battery
}

Lianshan Sun, ${ }^{1,2}$ Zheng Yi, ${ }^{1,2}$ Jing Lin, ${ }^{1,2}$ Fei Liang, ${ }^{1}$ Yaoming $W u,{ }^{1}$ Zhanyi Cao, ${ }^{*}{ }^{2}$ and

$$
\text { Limin Wang *1 }
$$

${ }^{1}$ State Key Laboratory of Rare Earth Resource Utilization, Changchun Institute of Applied Chemistry, CAS,

$$
\text { Changchun 130022, China }
$$

\footnotetext{
${ }^{2}$ College of Materials Science and Engineering, Jilin University, Changchun 130022, China
}

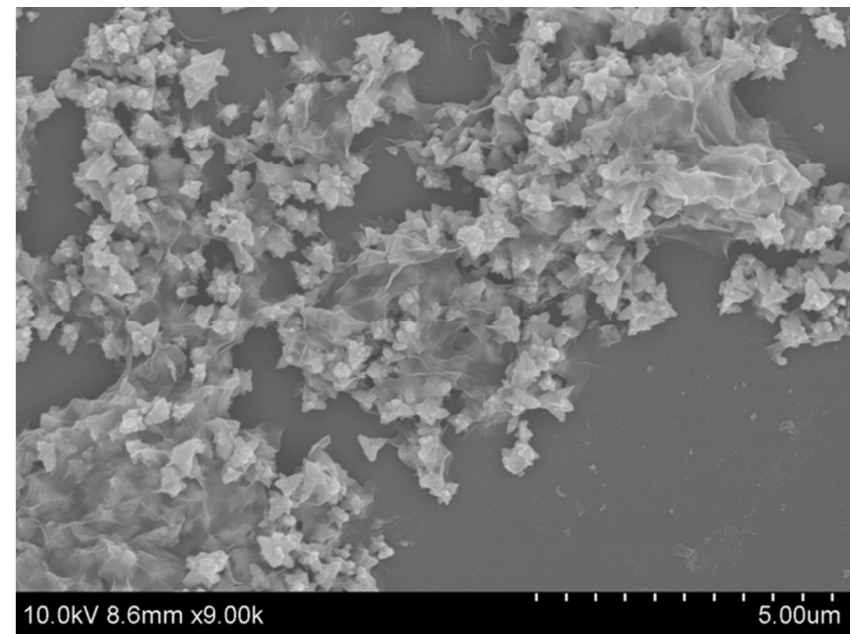

Figure S1: SEM image of $\mathrm{ZnO} @ \mathrm{RGO}$ synthesized by direct reaction of $\mathrm{Zn}\left(\mathrm{NO}_{3}\right)_{2}$ and GO with $\mathrm{NaBH}_{4}$ in solution. 

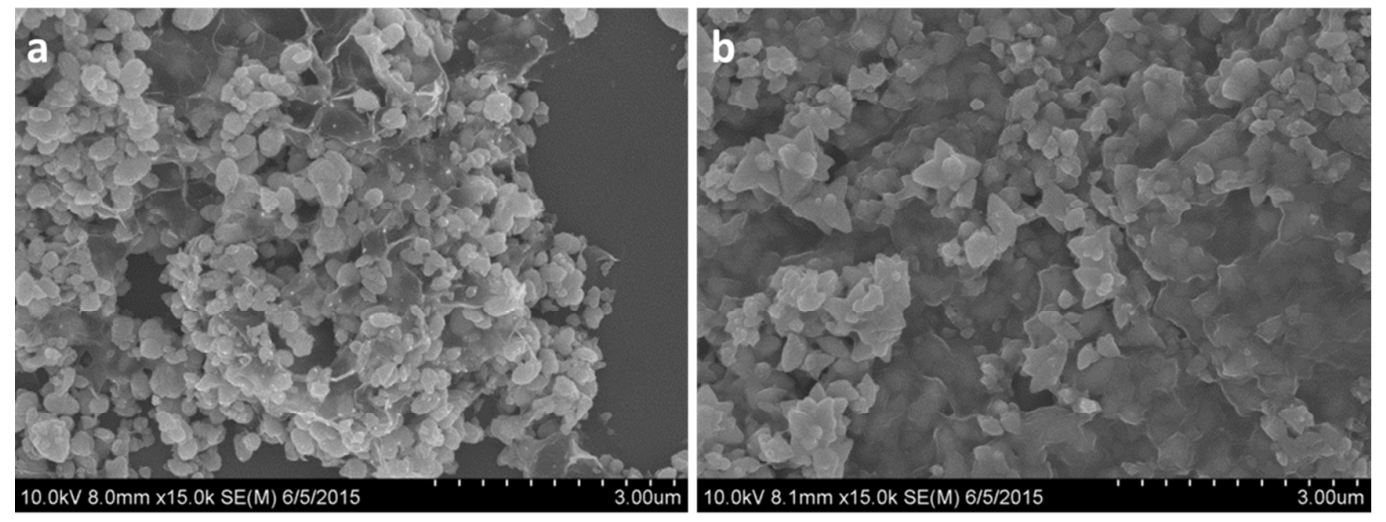

Figure S2: SEM images of ZnO@RGO synthesized by a first reaction of $\mathrm{NaOH}$ and $\mathrm{Zn}\left(\mathrm{NO}_{3}\right)_{2}$ to form

$\mathrm{ZnO}$ and then be reduced by $\mathrm{NaBH}_{4}$, (a) no PVP addition and (b) PVP addition in the initial.

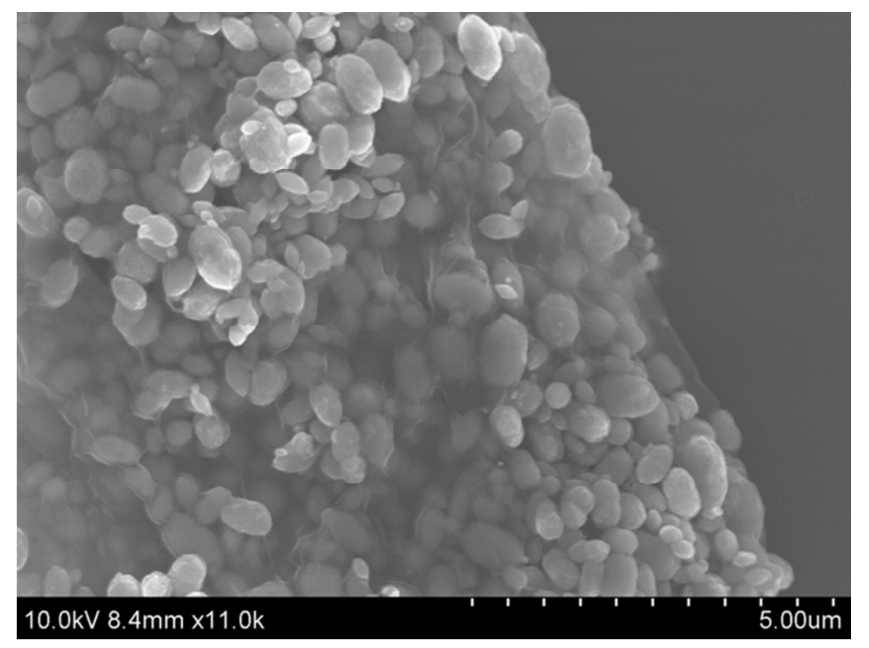

Figure S3: SEM image of ZnO@RGO synthesized with LiOH as the precipitator. 


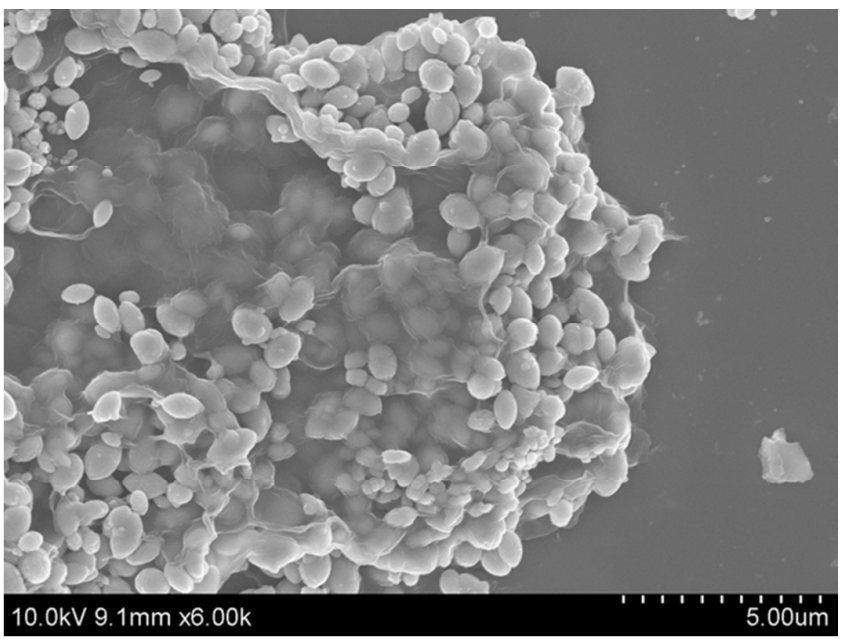

Figure S4: SEM image of ZnO@RGO with 6 mg RGO addition.
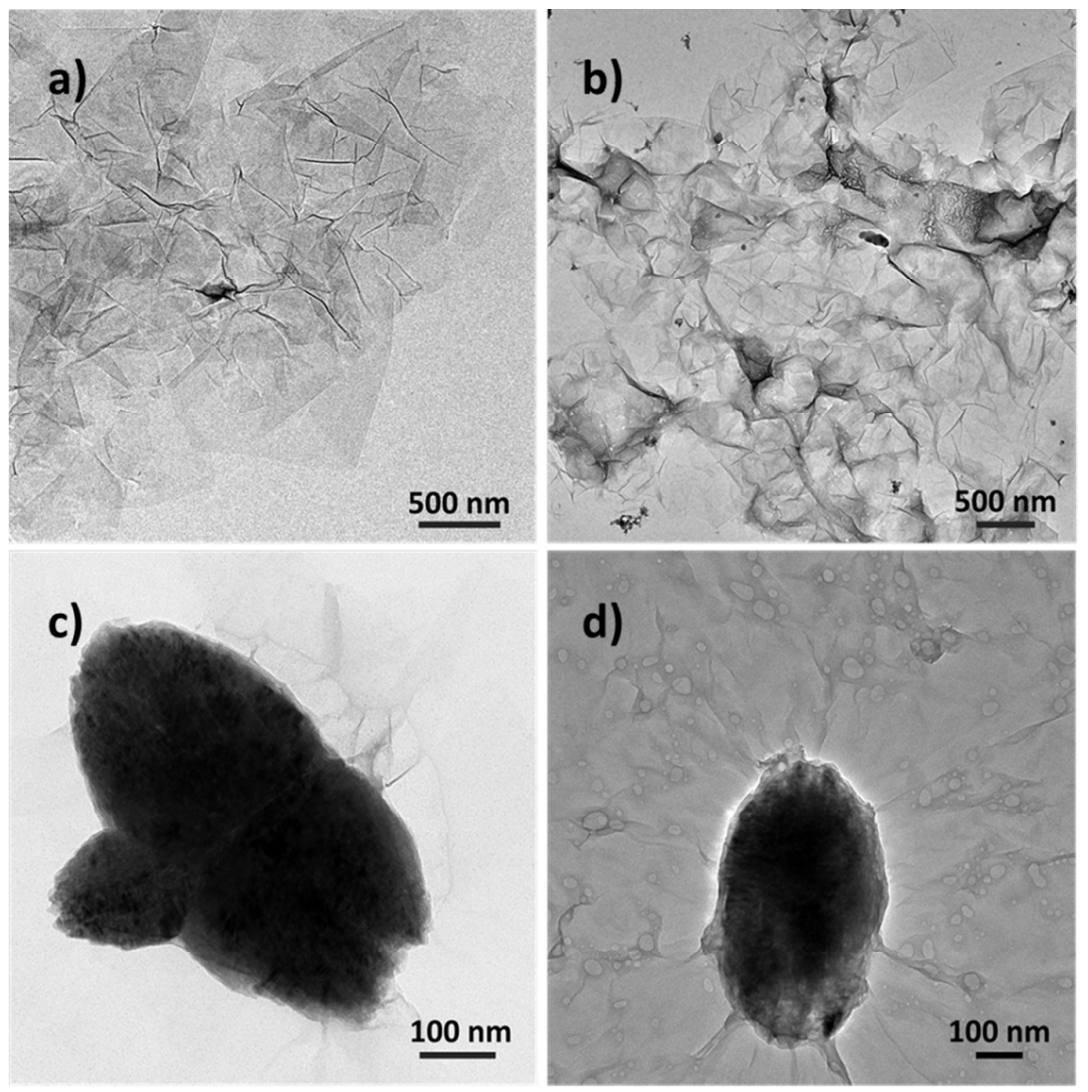

Figure S5: TEM images of (a) GO, (b) RGO, (c) ZnO@GO and (d)ZnO@RGO. 


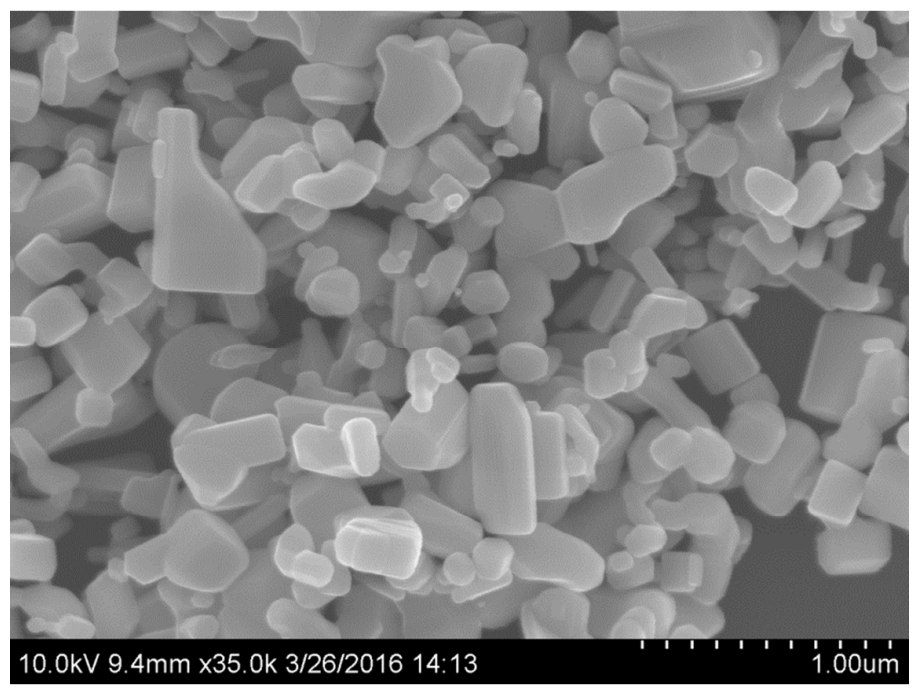

Figure S6: SEM image of commercial ZnO.

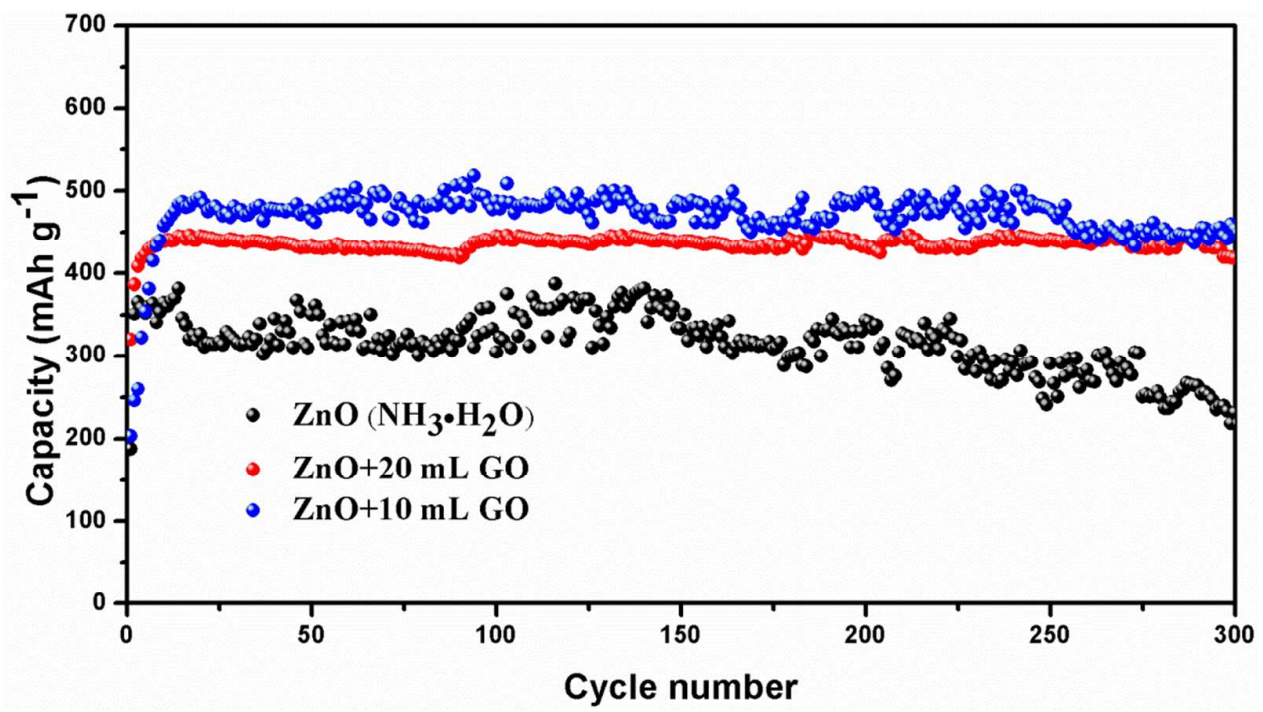

Figure S7: Discharge performance of $\mathrm{ZnO}$ without $\mathrm{RGO}$ and $\mathrm{ZnO}$ coating with different amount of

RGO. Compare with Fig. 5, the as-obtained ZnO has a discharge capacity of $395 \mathrm{mAh} \mathrm{g}^{-1}$ which is lower than capacity of $410 \mathrm{mAh} \mathrm{g}^{-1}$ of commercial ZnO. Three precursor ratios of ZnO@RGO composites with $10 \mathrm{~mL}$ (6.9 wt \%, $6 \mathrm{mg}), 15 \mathrm{~mL}$ (10 wt \%, $9 \mathrm{mg}$ ) and $20 \mathrm{~mL}$ (12.9 wt \%, $12 \mathrm{mg}) \mathrm{GO}$ coating are prepared. As RGO coating amount increase, the cycle stability of the composite is obviously enhanced. However, RGO is not active material and could not provide effective capacity. Thus, the discharge capacities of the composites rise first and then fall. 